negotiators - they don't haggle or compromise," reflects McKibben. Tied to her film The Age of Stupid, Armstrong also leads a numberbased campaign: '10:10' calls for a reduction in UK carbon emissions by 10\% in 2010 .

Human rights is an area of universal concern that can be effective in building consensus, as exemplified by Beijing's ice sculpture. Another motivator is the ethical pressure that lies behind the language of green marketing. Although sustainably designed products promote consumption through their desirability, they offer an easy route for individual action. As a prelude to COP15, Copenhagen last month hosted a design week to showcase sustainable Scandinavian flair, from fair-trade products and energy-saving devices to city parks and cycleways.

Audience fragmentation, a long-standing legacy of marketing, must also be overcome by communicators. Online multimedia projects can reach diverse audiences that are used to being selectively targeted by the media. One such project is 100 Places to Remember Before They Disappear, organized by Stine Norden and Søren Rud of Danish communications firm $\mathrm{Co}+\mathrm{Life}$, which combines a website with short television programmes, educational

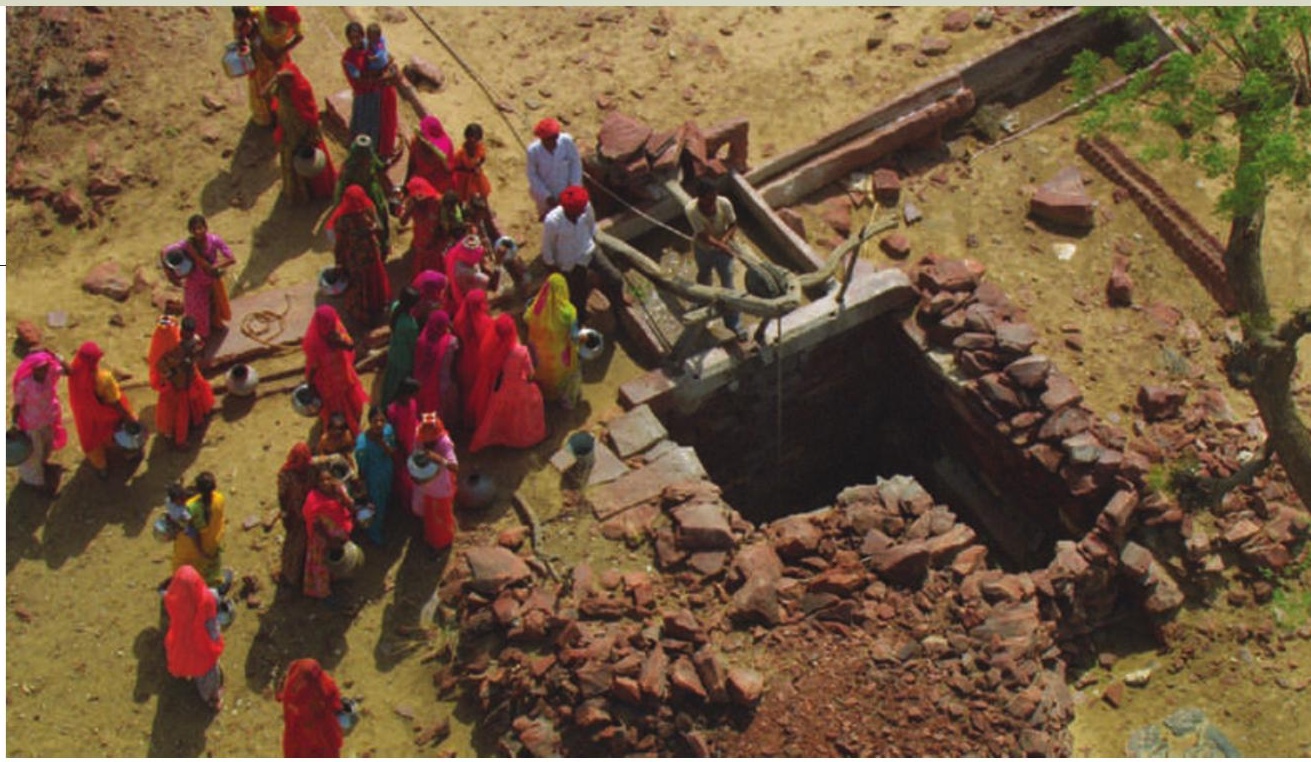

Women queue for water at a well near Khudiala in Rajasthan, India, in Yann Arthus-Bertrand's film Home.

materials and a travelling photographic exhibition to raise awareness and present climate solutions. It highlights characterful locations that have been identified by the Intergovernmental Panel on Climate Change as being at risk of loss in the next 30-60 years - including The Battery in New York City; Rotterdam in the Netherlands; Mount Kilimanjaro in Tanzania; and Perth, Australia.

So far, the cultural climate debate seems to have been dominated by palpable environmental concerns such as melting glaciers - perhaps because of the dramatic visual evidence they provide. But the loss of place and habitat affects people's well-being and resilience, bringing with it the severe threat of drought and disease. Promoting such concern over global health would put a human face on climate change - this may be the impetus we need to form a worldwide consensus for action.

Sanjay Khanna is a climate-change writer and journalist based in Vancouver, Canada.

e-mail: sanjaykhanna1@gmail.com

See Editorial, page 1027, and online at www.nature. com/roadtocopenhagen

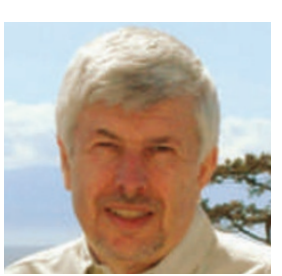

\title{
Q\&A: The science of persuasion
}

Psychologist Robert Gifford is co-author of a recent American Psychological Association report that examined the interface between psychology and climate change. He explains what makes people receptive and how to get messages about climate science across effectively.

\section{Why do climate scientists who speak to the public face a paradox?}

Scientists understand that climate models inherently have uncertainty. But as soon as the public experiences some uncertainty in the message, people begin to dither and to say, "Well, I guess it's not so urgent - the experts aren't so sure of themselves".

\section{How can climate campaigners make themselves heard?}

Messages have to be carefully targeted to different demographic groups, based on their self-interest. For the older generation, it's about their children and grandchildren; and for the younger generation, it's about them and their generation.

\section{How useful are phrases such 'climate justice'?}

For people with social-justice concerns, such a phrase will work. It resonates with members of Greenpeace and of left-leaning political parties; people more on the right side of the political spectrum will say, "You take care of your problems, we'll take care of ours".

\section{What five elements make up an effective message?}

First, it has to have some urgency. Second, it has to have as much certainty as can be mustered with integrity. Third, there can't be just one message: there must be messages targeted to different groups. Fourth, messages should be framed in positive terms. Evidence from a recent thesis I co-supervised shows that people are less willing to change their behaviour if you tell them they have to make sacrifices. If you tell them they can be in the vanguard, be a hero, be the one that helps that works. Fifth, you have to give people the sense that their vote counts and that their effort won't be in vain.

\section{If some commentators are right and we are past the point of no return, how could}

\section{we mobilize people into action?}

The same five elements would apply, except that the messages would emphasize adaptation and mitigation. We would need to tell people they can lessen the impact and be someone who helps our own and other species — but with a tilt towards communicating that there will be huge impacts.

\section{How do we communicate difficulties while making clear there are myriad options to be constructive?}

We can learn from the success of other campaigns, such as seat-belt, anti-alcohol or anti-smoking campaigns. The fear-appeal approach can be overdone to the point where it has a counteractive effect. Things should be presented more in terms of asking how each person is going to help us face the challenge. Saying "It's all over" makes people give up. Interview by Sanjay Khanna.

\section{See report at http://tinyurl.com/yfaobrg}

